Article

\title{
Predicting Social Networking Site Use and Online Communication Practices among Adolescents: The Role of Access and Device Ownership
}

\author{
Drew P. Cingel ${ }^{1}$, Alexis R. Lauricella ${ }^{1}$, Ellen Wartella ${ }^{1}$ and Annie Conway ${ }^{2}$ \\ ${ }^{1}$ Center on Media and Human Development, Northwestern University, 2147 Frances Searle Building, 2240 Campus \\ Drive, Evanston, IL 60208, USA; E-Mails: drewc@u.northwestern.edu (D.P.C.), alexislauricella@gmail.com (A.R.L.), \\ ellen-wartella@northwestern.edu (E.W.) \\ ${ }^{2}$ Chicago Architecture Foundation, 224 South Michigan Ave, Chicago, IL 60604, USA; \\ E-Mail: aconway@architecture.org
}

\section{How to Cite this Article}

Cingel, D. P., Lauricella, A. R., Wartella, E., \& Conway, A. (2014). Predicting Social Networking Site Use and Online Communication Practices among Adolescents: The Role of Access and Device Ownership. Media and Communication, $2(2), 1-30$.

\section{Copyrights}

(C) 2014 by the authors; licensee Cogitatio (Lisbon, Portugal). This article is licensed under a Creative Commons Attribution 4.0 International License (CC BY).

\section{Published by:}

\section{COGITATIO}

www.cogitatiopress.com

\section{About the Journal}

Media and Communication is an international open access journal dedicated to a wide variety of basic and applied research in communication and its related fields. It aims at providing a research forum on the social and cultural relevance of media and communication processes.

www.cogitatiopress.com/mediaandcommunication

\section{Editors-in-Chief}

Professor Bradley Greenberg, Departments of Communication and Telecommunication, Information Studies and Media, Michigan State University, USA

Professor Elisabeth Klaus, Department of Communication, University of Salzburg, Austria

\section{Managing Editor}

Mr. António Vieira, Media and Communication, Cogitatio Press, Portugal 
Article

\title{
Predicting Social Networking Site Use and Online Communication Practices among Adolescents: The Role of Access and Device Ownership
}

\author{
Drew P. Cingel ${ }^{1, *}$, Alexis R. Lauricella ${ }^{1}$, Ellen Wartella ${ }^{1}$ and Annie Conway ${ }^{2}$ \\ ${ }^{1}$ Center on Media and Human Development, Northwestern University, 2147 Frances Searle Building, 2240 Campus Drive, \\ Evanston, IL 60208, USA; E-Mails: drewc@u.northwestern.edu (D.P.C.), alexislauricella@gmail.com (A.R.L.), \\ ellen-wartella@northwestern.edu (E.W.) \\ ${ }^{2}$ Chicago Architecture Foundation, 224 South Michigan Ave, Chicago, IL 60604, USA; E-Mail: aconway@architecture.org \\ * Corresponding author
}

Submitted: 23 April 2014 | Published: 16 June 2014

\begin{abstract}
Given adolescents' heavy social media use, this study examined a number of predictors of adolescent social media use, as well as predictors of online communication practices. Using data collected from a national sample of 467 adolescents between the ages of 13 and 17, results indicate that demographics, technology access, and technology ownership are related to social media use and communication practices. Specifically, females log onto and use more constructive communication practices on Facebook compared to males. Additionally, adolescents who own smartphones engage in more constructive online communication practices than those who share regular cell phones or those who do not have access to a cell phone. Overall, results imply that ownership of mobile technologies, such as smartphones and iPads, may be more predictive of social networking site use and online communication practices than general ownership of technology.
\end{abstract}

Keywords: adolescents; cell phones; demographics; Facebook; Internet-capable mobile devices; online communication practices; predictors; social networking sites

\section{Issue}

This article is part of a regular issue of Media and Communication, edited by Professor Bradley Greenberg (Michigan State University, USA) and Professor Elisabeth Klaus (University of Salzburg, Austria).

(C) 2014 by the authors; licensee Cogitatio (Lisbon, Portugal). This article is licensed under a Creative Commons Attribution 4.0 International License (CC BY).

\section{Introduction}

There is little question that adolescents are the leaders of a growing trend to use social media in high quantities and on a daily basis (Lenhart, 2009a; Lenhart, 2009b; Lenhart, Purcell, Smith, \& Zickuhr, 2010; Madden et al., 2013). Recent studies examining adolescent Internet use have found that more than $90 \%$ of all $12-17$ year-olds use the Internet and $73 \%$ of adolescent Internet users spend time on social networking sites, an increase of nearly 20\% since 2006 (Lenhart et al., 2010). While use of other social networking sites is up from years past, a far smaller percentage of online adolescents (24\%) use Twitter compared to sites like Facebook (Lenhart et al., 2013). Additionally, research by Beasley and Conway (2011) found that a majority (59\%) of adolescents aged 8 to 17 check their Facebook profile page more than twice daily, compared to just $20 \%$ of adult users over the age of 18 . Although a majority of the research referenced in this paper refers to research conducted in the United States, it must be noted that Facebook is international in scope and is popular among adolescents throughout the world (boyd \& Ellison, 2008; Livingstone, 2008), becoming an important part of adolescents' daily lives, and changing the way that they communicate and interact with their friends and acquaintances (Whitlock, Powers, \& Eckenrode, 2006).

Overall then, a large majority of adolescents are using social media, especially Facebook, in relatively high quantities and multiple times each day. Based on this research, it is clear that the percentage of users is growing as social media use becomes more ubiquitous 
among adolescents. As a result, this study seeks to examine the predictors of social networking site use among adolescent users with a focus on the specific ways in which adolescents communicate and interact on these sites. We will utilize Uses and Gratifications as a framework for understanding how adolescents select and use communication technologies. Additionally, we will examine predictors of constructive and nonconstructive communication, defined as communication practices in which the adolescent either creates the communication (constructive), such as by posting a new status update, or receives the communication (non-constructive), such as by reading a friend's wall post. Online communication has been cited as a mechanism for understanding the effects of social networking site use on adolescents (Valkenburg \& Peter, 2008); therefore, it is important to understand demographic, access, and ownership predictors of such communication.

\section{Social Networking Sites}

\subsection{Effects}

With the growth in popularity of social media sites, multiple studies have explored the effects of social networking site use. For example, studies by Valkenburg and colleagues have demonstrated positive effects of social networking site use, such as helping adolescents explore their identity (Valkenburg \& Peter, 2008), increasing connections with others (Valkenburg \& Peter, 2008), and increasing users' self-esteem by increasing the number of relationships formed on the site and the number of comments received (Valkenburg, Peter, \& Schouten, 2006). Finally, recent research demonstrates that adolescents themselves indicate that social networking site use is more likely to have a positive effect than a negative effect on their social and emotional lives (Common Sense Media, 2012). Conversely, research indicates that there are potential risks for users of social networking sites as well. Research has demonstrated that youth may self-disclose intimate information (Valkenburg \& Peter, 2007) which is of particular concern, given that online self-disclosure is related to the posting of personally-identifying information (Christofides, Muise, \& Desmarais, 2011). For example, research by Barbosa and colleagues (2013) found that, among European and Brazilian adolescents, a large number of individuals reported posting information such as their full name, a photo of their face, their school, and even their address. Additionally, Peter, Valkenburg, and Schouten (2006) found that early adolescents (ages 12 to 14) were more likely to contact and communicate with a stranger using social media when compared to older adolescents.

\subsection{Use}

While other forms of social media, such as Twitter, do allow users to create profiles with a great amount of information, Facebook provides perhaps the greatest opportunity for doing so. Recent reports have indicated that adolescents have begun to split their social networking time across a number of different sites, such as Facebook, Twitter, and Tumblr (Madden et al., 2013). It is important to note, however, that Facebook remains the most used social networking site for the majority of adolescents (Madden et al., 2013).

Overall, Facebook allows users to create and monitor a profile, controlling the personal information that others can see on their profiles. This is important, especially to adolescents, given the great significance that interpersonal relationships hold during this developmental stage. After all, during adolescence, children attempt to maintain close ties to similar others in an effort to deal with increasing separation from their parents (Lapsley, FitzGerald, Rice, \& Jackson, 1989). Social media sites, such as Facebook, allow users to maintain relatively close ties to friends, family, and acquaintances, thereby alleviating the fear of losing relationships. Additionally, Facebook provides users with tools that allow them to change their profiles quickly and easily. Therefore, it is possible for Facebook users to post information that could allow them to explore their identity and connect with others, two positive effects of social media that have been identified in the literature (Goff, 2009; Valkenburg \& Peter, 2008). It is also likely, however, that Facebook users can use the options available to post potentially sensitive information. Although social networking sites, such as Facebook, do have privacy protections available that are used by a growing majority of adolescent Facebook users (Lenhart \& Madden, 2007; Patchin \& Hinduja, 2010), there are still users whose profiles are available to the entire Facebook community.

\section{Current Study}

Given the mixed findings of both positive and negative effects of social media site use on children and adolescents, and with social network use reaching near ubiquity with adolescent users, it is important that researchers explore the ways in which adolescents are using the features of social networking sites as a way of communicating and interacting with their peers. After all, it is these online communication practices that are generally cited as the mechanism by which both positive and negative effects occur (Valkenburg \& Peter, 2008). While there is a large and growing body of research on the effects of social media use among adolescents, less research has systematically looked at predictors of social media use among this age group, especially the ways teens communicate and interact online. Therefore, in the present study, we will first examine the pattern of relationships between adolescent demographics, access to technology, technology ownership, and overall social media usage. Next, these 
predictors (demographics, access to technology, and technology ownership) will be used to examine specific Facebook posting and communication practices including constructive and non-constructive communication practices.

\section{Predictors of Social Media Use}

\subsection{Ethnicity}

There has been consistent evidence of race and ethnicity differences in overall media use over the years. Most recently, reports indicate significant differences in the amount of time youth ages 8 to 18 years old spend using media as a function of race (Hargittai, 2007; Rideout, Lauricella, \& Wartella, 2011). While these numbers appear to exist for traditional media like television and computers, we know very little about the race or ethnicity differences in social networking site use. Recent data indicates no differences in teen Facebook use by race, but significantly more Black youth use Twitter than either White or Hispanic Youth (Madden et al., 2013). Given the historical differences in media use as a function of ethnicity, we control for ethnicity in many analyses in this study.

\subsection{Gender}

Regarding the overall use of social media sites, nationwide representative surveys of adolescents have generally found that a greater percentage of females had an online profile when compared to males. For example, Lenhart (2009a) found that $86 \%$ of surveyed females aged 15 to 17 reported having some type of online profile, compared to just $69 \%$ of males in that same age range. In addition, research by Beasley and Conway (2011) found that females aged 13 to 17 spend more time using social networking sites and log into them more than males do each day. Specifically, $25 \%$ of surveyed females reported checking their online profiles more than 5 times each day, double the percentage of males who reported doing so. Finally, using a slightly older sample (18 to 19 year-olds) Hargittai (2007) found that females represented a majority of social media users across four platforms: Facebook, MySpace, Xanga, and Friendster, although these were not always significant differences. Based on this body of research,

H1a: in the present sample, females will log onto social networking sites more frequently than males.

Concerning the type of communication practices used by males and females on social networking sites, research has also indicated some differences based on gender. For instance, Rosenberg and Egbert (2011) found that females were more likely to work towards achieving a number of goals on Facebook. For example, females were more likely to experiment with their online identity and the ways in which they interacted with others, working towards achieving a fuller sense of their identity and closer relationships with others (Rosenberg \& Egbert, 2011). According to the authors, these goals help to shape the planning of a message, as individuals focus on increasing and maintaining attention and emotional support. Additionally, these goals led to individuals thinking about their self-concept and therefore, engaging in social comparison (Rosenberg \& Egbert, 2011). In order to achieve these goals, it is likely that users would need to engage in more constructive communication strategies, in order to post information that can potentially increase others' attention to their profiles and their own sense of identity.

Additionally, Valkenburg and Peter (2007) found that girls aged 12 to 18 were more likely to be socially anxious than boys, in general. Further, socially anxious respondents were more likely to use the Internet and social networking sites for intimate self-disclosure. Again, it seems likely that constructive communication practices, such as posting new photos, updating one's status, or posting on a friend's wall, would need to be used for intimate self-disclosure. While these constructs, such as emotional support, social anxiety, and selfdisclosure, are rather disparate, it is important to note that constructive communication practices could be used by adolescents to achieve feelings of emotional support from others, reduce social anxiety, and increase their self-disclosure. The relationship between gender and non-constructive communication is unclear, however. Therefore,

$\mathrm{H} 1 \mathrm{~b}$ : in the present sample, controlling for age and ethnicity, females will be more likely to engage in constructive communication practices on social networking sites than males.

RQ1: controlling for age and ethnicity, what is the relationship between gender and non-constructive communication practices?

\subsection{Age}

Similar to the relationship between gender and social media use, the body of research on the relationship between age and social media use is generally consistent with social media use increasing with age during adolescence and early adulthood. For example, Lenhart and colleagues (2010) found that, while over $80 \%$ of online teens aged 14-17 used social media sites, just over $50 \%$ of online teens aged 12 to 13 did so. Further research by Beasley and Conway (2011) indicated a similar finding, with nearly $70 \%$ of $13-17$ year-old respondents reporting using social media compared to just $30 \%$ of $8-12$ year olds. Thus,

$\mathrm{H} 2$ : controlling for gender and ethnicity, age will be positively related to the number of social media log-ins per day.

In terms of specific communication practices on so- 
cial networking sites, research by Valkenburg and Peter (2007) indicated a curvilinear relationship between age and online self-disclosure, such that 15 year-olds were the most likely to engage in such behavior when compared to younger and older adolescents. While a number of other large-scale surveys have measured these practices (Beasley \& Conway, 2011; Lenhart, 2009a; Lenhart et al., 2010) few have examined the relationship with age, making this body of research less clear. Therefore,

RQ2: controlling for gender and ethnicity, what is the pattern of relationships between age (13-15 yearolds vs. 16-17 year-olds) and communication practices (both constructive and non-constructive) on social networking sites?

\subsection{Access to Technology and Ownership}

In addition to demographics, it seems highly likely that access to technology and ownership would be related to both the overall use of social networking sites and the types of communication practices employed by adolescent users. The relationship between technology ownership, access, and online communications practices can perhaps be best understood using the Uses and Gratifications framework (Katz, Blumler, \& Gurevitch, 1974). Under this framework, there are several assumptions that underpin an individual's use of media: communication behaviors are motivated, consumers are relatively active in their selection of media, social groups, such as friends and peers, motivate behavior, media compete with other channels for selection, attention, and overall use, and people are more influential in the media effects process than media themselves (Katz et al., 1974).

Using this framework and past research, it is likely that adolescents are especially engaged when selecting and using media. After all, users are generally interested in the utility of a particular technology, and are therefore both interested and motivated to use it (Palmgreen, Wenner, \& Rosengren, 1985). Based on this research, if an adolescent perceived that a technology was useful in some way, such as for sending messages to friends, accessing the Internet, or monitoring ones' social networking profile page, he or she would be more likely to use that technology, and use it in specific ways. Previous research has found that perceived utility of a particular technology is a powerful predictor of use among adolescents (Cingel \& Sundar, 2012). This, of course, assumes that adolescents have access to such technologies. Research has shown that teens do have access to a number of new technologies, such as cell phones, video game consoles, computers/tablet computers (Lenhart, Ling, Campbell, \& Purcell, 2010), all of which give teens the opportunity to access the Internet. In fact, teens spend nearly as much time online as do adults, with $77 \%$ percent of adolescents spending over 1 hour online each day, much of that on social networking sites (Beasley \& Conway, 2011). Using the example of social media use under this framework, one can imagine why adolescents would be motivated to select and use social networking sites. After all, it is something that their peer group engages in with great frequency (Lenhart et al., 2010), and given the importance of interpersonal relationships and friendships during this developmental period (Sullivan, 1953), adolescents likely see social networking use as critical to their social and emotional wellbeing. Therefore, with a sense of perceived utility and the motivation for use coming from close social groups and other friends, it makes sense that the number of Internet-capable technologies owned or accessible by an adolescent, the more likely they would be to access social networking sites. Therefore, we predict:

$\mathrm{H} 3$ : there will be a positive relationship between the number of Internet-capable technologies accessible by an adolescent, the likelihood of having a social networking profile, and log-on frequency.

\section{Predicting Communication Practices on Social Networking Sites}

In the present study, however, we are not only interested in predicting overall use of social media; additionally, we are interested in predicting specific communication practices on social networking sites. We argue that when users choose to post on Facebook, update a status, or post on a friend's wall, they are actively selecting this medium due to its perceived convenience and utility in the communication experience; it allows them to communicate rapidly and easily with their friends, family, and others. Therefore, they have a communication intention in mind, are involved in the experience, and thereby are actively engaging in communication (Blumler, 1979; Rubin, 1993). Here, we refer to these practices as constructive communication practices (e.g. updating one's status, posting on a friend's wall). In regards to constructive communication practices, the user has an intention in mind when engaging in this process; thus, they are generally involved and active as they work to construct a certain communication. In regards to nonconstructive communication practices (e.g., watching a video on a friend's wall), while the user has actively selected the medium for its utility, they may not intend to communicate (explaining why they are clicking on other links), and are not as involved in the experience as they would be if they were the one posting the information (Blumler, 1979; Rubin, 1993). Rather, although involved in communication, when users are engaging in these non-constructive communication practices, they are not actively involved the creation of the communication.

Both qualitative and quantitative research has indicated some possible predictors of adolescent online 
communication practices. First, Pempek, Yermolayeva, and Calvert (2009) found that, among a college-aged sample, users engaged in both content creation (which could include posting pictures or adding new information) and observing content (which could include reading information on others' walls or looking at others' photos). Although these researchers did not specifically ask where users were engaging in these practices (e.g., on a personal computer or in a public computer lab), it should be noted that this research indicates that social networking site users do engage in a blend of both constructive and non-constructive online communication practices. Using an adolescent sample, research by Lenhart et al. (2010) found that teen ownership of technology, specifically cell phones, was related to using the technology for a broader number of purposes, such as sending more text messages or taking videos, which could include different communication practices.

Given the evidence cited previously, it is not surprising that owning Internet-capable devices would be related to increased use, due to the heightened accessibility afforded by not having to share the technology with someone else and the possibility of having the technology on one's person throughout the day. It also appears that adolescent owners of technology would be more likely to engage in constructive communication practices on social networking sites for a few reasons. First, given heightened accessibility, adolescent technology owners would likely have more time to communicate in general on social networking sites, and especially have more time to engage with others by carrying on online conversations through private messages, instant messages, and wall posts. With the growing number of adolescents that use the privacy features on social networking sites (Lenhart \& Madden, 2007; Patchin \& Hinduja, 2010), it is also likely that adolescents may think about others' ability to see what they are posting on social networking sites. Being the sole owner of a particular technology may address this concern, as adolescents could control who might see their posted information in both on- and offline settings. For example, Livingstone (2009) found that social networking sites give adolescents privacy from their parents, as adolescents work to connect with friends and therefore become more independent. Therefore, given that adolescents seek privacy from parents, adolescents with more access to private or personal technologies would be more likely to engage in constructive communication practices.

Although these practices were not referred to as constructive communication practices in these previous studies, each practice does require the user to actively select a medium based on a perception of utility. Also, the user must have some communication intention in mind, and thus, should be somewhat involved in the process. Therefore, these practices would all fit into the constructive communication framework as it is defined in the present study. In sum, adolescents should engage in more constructive communication practices, due to the privacy afforded by not having to share the device with someone who they might not want to share the information. It is unclear, however, if access to these technologies will be related to non-constructive communication. Therefore,

H4a: adolescents who primarily use a private home computer will use more constructive communication practices on their profile than adolescents who primarily use a shared home computer or adolescents who primarily use public computers.

H4b: adolescents who own a smartphone will use more constructive communication practices on their profile than adolescents who share a smartphone, own or share a regular phone, or those who don't own or share a cell phone.

H4c: adolescents who own Internet-capable mobile devices, such as iPod Touches, iPads, or other tablet computers, will use more constructive communication practices on their profile than adolescents who do not own any of these technologies.

RQ3: what is the pattern of relationships between private computer, smartphone, and tablet ownership and non-constructive communication practices?

\section{Method}

\subsection{Participants}

Overall, 909 children and adolescents between the ages of 8 and 17 completed an online survey instrument designed by the Museum of Science and Industry in Chicago, Illinois, USA during summer 2011. In the present study, we use data collected from 467 participants between the ages of 13 and 17 for analysis, as only this set of participants was asked about social networking site use. Although younger children do indeed use social networking sites, the largest, Facebook, is legally closed to individuals younger than age 13 . In total, participants represented 48 states in the US, making the sample national in scope. There were no biases in terms of gender, age, race, or type of schooling. For a listing of demographic data collected from 13- to 17year old participants, please see the 'demographics' section below.

\subsection{Procedure}

Once the survey instrument was created by the Museum of Science and Industry, Chicago, it was given to the market research firm MarketTools, which uses an ongoing consumer panel, for distribution. Parents of children ages 8 to 17 were contacted via email and asked to allow their child to complete the online survey. The link to the online survey was embedded in this email. 
Participants were selected based on their child's gender, race, age, and home address in the United States. Once parents gave their permission, children and adolescents completed the survey, which took an average of 20 minutes.

\subsection{Measures}

\subsubsection{Demographics}

As part of the survey, participants were asked about their gender, age, race, and schooling. In the present sample, males made up a slight majority (54.8\%). Almost $19 \%$ of the sample were 13 year-olds, $19.9 \%$ were 14 year-olds, $25.7 \%$ were 15 year-olds, $18.4 \%$ were 16 year-olds, and $17.3 \%$ were 17 year-olds. In regard to race, $80.0 \%$ were Caucasian, $7.6 \%$ were AfricanAmerican, 5.9\% were Hispanic/Latino, and 5.9\% were Asian. Just over $83 \%$ attend public school, $10.5 \%$ attend to private school, $3.2 \%$ attend a charter school, and $3.2 \%$ were homeschooled. Median household income of participants was between $\$ 30,000$ and $\$ 40,000$.

\subsubsection{Technology Access and Ownership}

Participants were asked about their access to Internetcapable technologies and their ownership of such technologies. Specifically, participants were asked where they accessed the Internet: at home on their own computer (69.1\%), at home on a computer they shared (41.8\%), at school $(45.8 \%)$, at the library $(16.1 \%)$, or at a friend's house $(28.1 \%)$. These percentages do not sum to $100 \%$ because these categories were not mutually exclusive.

Next, participants were asked if they had access to a smartphone (identified as a Blackberry, iPhone, or Android phone) or a regular phone (identified as any other type of phone that did not connect to the Internet). Nearly $60 \%$ had access to a regular phone, $25.9 \%$ had access to a smartphone, and $14.3 \%$ did not have access to either. The next question asked if they owned the phone from asked about in the previous question. Here, $80.7 \%$ reported that they did own the phone, whereas $13.2 \%$ reported that it was their mom or dad's phone, and $6.1 \%$ reported that it belonged to someone else in the family.

Finally, participants were asked if they owned any of the following Internet-capable mobile technologies: iPod Touch (27.5\%), iPad (8.4\%), Android Tablet (such as the Motorola Xoom) (3.5\%), or a Windows Tablet (2.2\%). Fifty-eight percent did not have access to any of these technologies. This was not a mutually exclusive variable, allowing respondents to indicate if they owned more than one of each of these Internetcapable mobile technologies.

In order to measure adolescents' overall access to Internet-capable technologies, their responses to the previously described three sections were summed. Therefore, this measure included the number of com- puters that they had access to (personal, shared, school, library, or friend's), whether or not they had access to a smartphone (one they owned or their parent's/relative's), and the number of Internet-capable mobile devices they owned (either iPod Touch, iPad, Android Tablet, or Windows Tablet). Overall, adolescents had access to an average of $2.93(S D=1.88)$ Internetcapable devices.

To measure technology ownership, we broke the types of technologies into three groups: computer, cell phone, and Internet-capable mobile devices. Computer ownership was then broken into two groups based on the computer that adolescents generally used to access the Internet: either from home on their own computer, or from home on a computer they shared. While it was possible to report using both a private and shared computer, those who reported having both were put into the private computer ownership group. Additionally, although some adolescents reported not having access to any computers at home, there were not enough in this group for statistical analysis. Overall, $72.3 \%$ of adolescents reported having their own computer, while $27.7 \%$ reported sharing a computer. Cell phone ownership was broken into 5 groups: adolescents who reported owning a smartphone (24.8\%), adolescents who reported using their parent or relative's smartphone $(0.9 \%)$, adolescents who reported owning a regular phone $(50.9 \%)$, adolescents who reported using their parent or relative's regular phone (9.1\%), and adolescents who did not own or have access to either smartphones or regular phones (14.4\%). Finally, Internet-capable mobile device ownership was broken into two groups: those who reported owning at least one iPod Touch, iPad, Android Tablet, or Windows Tablet (64\%), and those who did not own any of these devices (36\%).

Adolescents' social media use was measured in two ways. To measure the total number of social networking profiles created, adolescents were given a list of 16 different social networking sites (e.g. Twitter, Facebook, Myspace, Stumbleupon, Bebo) and asked to check all of the sites they used at least once a month. The total number that each participant checked was summed in order to measure their total social networking profile ownership. Adolescents reported creating an average of 1.32 profiles $(S D=1.55)$. Secondly, adolescents were asked to respond, using a 1-7 Likert-type scale anchored by 'never' and 'more than five times a day', how often they checked a social networking site each day. Participants scored a mean of $5.52(S D=1.20)$. This indicates an average response between 'once a day' and 'two to five times a day'.

\subsubsection{Social Media Communication Practices}

Given the near ubiquity of Facebook use among the present sample, social media communication practices were measured by asking participants 13 items de- 
signed to assess how often they engaged in a number of activities on Facebook, such as posting photos, posting on a friend's wall, posting status updates, watching a video, or clicking a link. These responses were measured using a 1-5 Likert-type scale anchored by 'never' and 'daily'. An exploratory principal-components factor analysis with varimax rotation yielded two dimensions with eigenvalues greater than 1 . These two dimensions accounted for $62.86 \%$ of all variance and all items fell on their respective dimension with a factor loading greater than 0.60 and a factor loading on the other dimension lower than 0.40. One item ("How often do you play a game such as Farmville") did not load on either factor and was therefore dropped. Overall, 8 items loaded on the first factor (e.g. "How often do you post on a friends wall?", "How often do you post status updates about your life on Facebook?", and "How often do you comment on a friend's post?"). This factor was called constructive communication practices, because each of the practices involved the user actively posting or otherwise communicating some type of information on Facebook. The other factor, which we call non-constructive communication, consisted of 4 items (e.g. "How often do you click through a link in your News Feed or on a friend's wall?", "How often do you share a post from your News Feed?", and "How often do you share news articles, videos, or links from other sites with your fiends via Facebook?"). Both constructive (Cronbach's $\alpha=0.88$ ) and non-constructive communication practices (Cronbach's $\alpha=0.85$ ) were reliable.

\section{Results}

\subsection{Ethnicity}

Due to inadequate numbers of respondents in each ethnic group we could not analyze the data with ethnicity as a predictor of social networking use. Rather, we included it as a control variable in later analyses.

\subsection{Gender}

H1a predicted that females in the present sample would log onto Facebook more often than males after controlling for age and ethnicity. This hypothesis was tested by using an ANCOVA, which indicated a significant relationship $(F(1,364)=5.96, p<0.05)$. Specifically, females $(M=5.68, S D=1.19)$ reported logging into Facebook more frequently than males $(M=5.37, S D=1.19)$. Thus, H1a was supported.

$\mathrm{H} 1 \mathrm{~b}$ predicted that females in the present sample would be more likely to engage in constructive communication practices on social networking sites after controlling for age and ethnicity. An ANCOVA was used to test this hypothesis. Results indicated a significant finding $(F(1,360)=9.92, p<0.01)$. Specifically, females reported engaging in more constructive communication practices $(M=3.65, S D=0.88)$ than males $(M=3.35$,
$S D=0.91)$. Therefore, these data support the predicted relationship in $\mathrm{H} 1 \mathrm{~b}$.

RQ1 asked if there is a relationship between gender and non-constructive communication practices and was tested using an ANCOVA. Unlike $\mathrm{H} 1 \mathrm{~b}$, results were not significant $(F(1,360)=2.51, p=n$.s. $)$. Thus, there is no relationship between gender and non-constructive communication practices, providing an answer for RQ1. The results of this first set of hypotheses indicate that females log onto their profiles more frequently and engage in more constructive communication practices on their profile than males do. There is no relationship between gender and non-constructive communication.

\subsection{Age}

$\mathrm{H} 2$, which asked if adolescents aged 16 to 17 would log into their social networking profiles more than adolescents aged 13 to 15, was tested using an ANCOVA with gender and race as control variables. This test was not significant $(F(1,360)=0.52, p=$ n.s. $)$. Therefore, older adolescents $(M=5.59, S D=1.05)$ are not more likely to log into social media sites during the day when compared to younger adolescents $(M=5.47, S D=1.28)$, which provides an answer to $\mathrm{H} 2$. Another ANCOVA was used to test RQ2, which asked about the pattern of relationships between age and communication practices on social media sites. Results indicated that older adolescents $(M=3.52, S D=0.84)$ did not use more constructive communication practices on social media sites when compared to younger adolescents $(M=3.47$, $S D=0.95)(F(1,356)=0.14, p=n$.s. $)$. There also was no significant relationship between age groups and nonconstructive communication practices after controlling for gender and ethnicity $(F(1,360)=0.21, p=$ n.s. $)$. Taken together, this provides an answer to the question posed in RQ2. Overall, there was no difference between younger and older adolescents in terms of the frequency with which they logged into social networking sites or their online communication practices.

\subsection{Access}

$\mathrm{H} 3$, which predicted a positive relationship between an adolescent's access to Internet-capable technologies, the number of online social media profiles they created, and the frequency of logging on to those profiles, was tested using two hierarchical multiple regressions. With the number of adolescent online profiles as the dependent variable, the control variables of gender, race, and age were entered on the first step and were significant $\left(R=0.14, R^{2}=0.02, F(3,460)=2.91, p<0.05\right)$. Adolescent access to Internet-capable devices was entered on step two. This was significant as well $\left(\Delta R^{2}=\right.$ $0.23, p<0.01 ; B=0.49, p<0.01)$. Therefore, adolescents with access to more Internet-capable technologies report having more online social networking profiles. 
For the second hierarchical multiple regression, the frequency of logging on was entered as the dependent variable. Again, gender, race, and age were entered as control variables, but were not significant $\left(R=0.13, R^{2}\right.$ $=0.02, F(3,463)=2.18, p=$ n.s. $)$. The frequency of logging on to social networking sites was entered on step two and was significant $\left(\Delta R^{2}=0.02, p<0.01 ; B=\right.$ $0.15, p<0.01)$. Therefore, adolescents with more access to Internet-capable devices have more social networking profiles and log into those profiles more often than those with less access to Internet-capable devices. These results provide support for $\mathrm{H} 3$.

\subsection{Ownership}

$\mathrm{H} 4 \mathrm{a}$ predicted that adolescents who had their own private computer would use more constructive communication on their social networking profiles than adolescents who used a shared home computer or a public computer. An ANCOVA with gender, race, and age as control variables was used with constructive communication practices as the dependent variable. This was not significant $(F(1,354)=0.36, p=n$.s. $)$. An ANCOVA with the same controls was also used to test non-constructive communication practices. This test was not significant as well $(F(1,354)=0.98, p=n . s$. $)$. Therefore, computer ownership does not appear to influence the communication practices on social networking sites among adolescents, and thus, $\mathrm{H} 4 \mathrm{a}$ was not supported.

An ANCOVA with gender, race, and age as controls was also used to test $\mathrm{H} 4 \mathrm{~b}$, which predicted that adolescent smartphone owners would engage in more constructive communication practices on those profiles than adolescents who shared a smartphone with a parent, adolescents who either owned or shared regular phones, or adolescents who did not have access to any mobile phones. With constructive communication practices as the dependent variable, results were significant $(F(4,357)=3.58, p<0.01)$. Post-hoc tests with a Bonferroni adjustment indicated that smartphone owners $(M=3.76, S D=0.80)$ differed significantly from regular cell phone sharers $(M=3.19, S D=0.92)(p<$ $0.05)$, and adolescents with no access to cell phones ( $M$ $=3.20, S D=1.00)(p<0.01)$ (see Table 1$)$. For nonconstructive communication practices, results were $\operatorname{similar}(F(4,357)=3.22, p<0.05)$. Specifically, adolescent smartphone owners engaged in significantly more non-constructive communication practices $(M=3.20$, $S D=1.00)$ than adolescents who did not report owning a smartphone $(M=2.59, S D=1.04)$, although these numbers were lower than those for constructive communication. In sum then, adolescents who own a smartphone engage in more constructive communication practices than regular cell phone sharers and adolescents who do not have access to a cell phone. These results offer partial support for H4b. Additionally, smartphone owners also engage in more nonconstructive communication practices than those who do not own a phone.

Finally, $\mathrm{H} 4 \mathrm{C}$ was tested using an ANCOVA with gender, race, and age as controls. This hypothesis predicted that adolescents who owned Internet-capable mobile devices, such as iPod Touches or iPads would engage in more constructive communication practices than adolescents that did not own such technologies. With constructive communication practices as the dependent variable, results were significant $(F(1,360)=6.44, p<$ $0.05)$. Specifically, Internet-capable mobile device owners scored higher on the measure of constructive communication practices $(M=3.65, S D=0.88)$ than adolescents who did not own any of these technologies $(M=$ 3.39, $S D=0.91)$. These results provide support for $\mathrm{H} 4 \mathrm{c}$. For non-constructive communication behaviors, results were significant as well $(F(1,360)=12.98, p<0.01)$. Similar to results for constructive communication, mobile technology owners engaged in significantly more nonconstructive communication $(M=3.17, S D=1.11)$ that those who did not report owning Internet-capable mobile devices $(M=2.74, S D=1.04)$. Taken together, and similar to results for constructive communication, smartphone and mobile device, but not computer, ownership was related to increased non-constructive communication practices, providing an answer for RQ3.

\section{Discussion}

\subsection{Summary of Findings}

Overall, results indicate that adolescent demographics, access to technology, and technology ownership are predictive of both the frequency of social media log-ins as well as constructive communication practices. Specifically, data indicate that females tend to log into their social media profiles more often than males. Also, females were more likely to engage in constructive, but not non-constructive, communication practices when compared to males, making gender one predictor of social media use and certain types of communication practices. Age, however, was not a predictor, as it was not related to either log in behavior or communication practices.

In terms of access to technology, those with greater access reported having more social media profiles on multiple sites. Additionally, those with greater access also reported logging into those profiles more frequently than those with less access. Therefore, technology access, which in the present study included access to computers, cell phones (both smartphones and regular phones), and Internet-capable devices (such as iPads and tablet computers), is another predictor of both adolescent social media log-in behavior and online communication practices. 
Table 1. Differences between Technology Ownership on Constructive Communication.

\begin{tabular}{llc}
\hline & $M$ & $S D$ \\
\hline Computer Ownership & & \\
Computer Owner & $3.52^{\mathrm{a}}$ & 0.92 \\
Computer Sharer/No access & $3.47^{\mathrm{a}}$ & 0.86 \\
Mobile Phone Ownership & & \\
Smartphone Owner & $3.76^{\mathrm{a}}$ & 0.80 \\
Smartphone Sharer & $3.38^{\mathrm{a}, \mathrm{b}}$ & 0.35 \\
Regular Phone Owner & $3.50^{\mathrm{a}, \mathrm{b}}$ & 0.90 \\
Regular Phone Sharer & $3.19^{\mathrm{b}}$ & 0.92 \\
No Phone & $3.17^{\mathrm{b}}$ & 1.01 \\
Mobile Device Ownership & & \\
Mobile Device Owner & $3.64^{\mathrm{a}}$ & 0.88 \\
Mobile Device Sharer/No access & $3.40^{\mathrm{b}}$ & 0.91 \\
\hline Note: superscripts ${ }^{\mathrm{a}}$ and ${ }^{\mathrm{b}}$ are used to indicate significant differences between the means within each technology \\
$\begin{array}{l}\text { ownership category. Means that do not share a common superscript in the same technology ownership category } \\
\text { differ significantly at } p<0.05 .\end{array}$
\end{tabular}

Finally, results indicated that adolescents with access to a personal computer were no more likely to engage in constructive or non-constructive communication practices than adolescents who only had access to a shared computer or no access at all. Smartphone owners, however, engaged in more constructive practices than adolescents who shared a regular phone or adolescents who did not have access to any type of mobile phone. Lastly, results indicated that adolescents who owned Internet-capable mobile devices engaged in more constructive and nonconstructive communication practices than adolescents who did not own any of these devices. Overall then, results indicate that mobile device ownership, and not necessarily technology ownership of all kinds, was generally predictive of constructive and non-constructive communication practices among adolescents.

\subsection{Implications}

Practically, these findings are important, especially those that elucidate predictors of constructive communication practices on social networking sites. Overall, it appears that not all types of owned technology are related to increases in such communication practices online. Specifically, mobile technologies, such as smartphones and Internet-capable mobile devices like iPads and tablet computers, were related to increases in constructive communication practices, whereas having a personal computer was not related to any increase. This perhaps indicates the role that mobile technologies play in social networking use and online communication practices. After all, as predicted under the Uses and Gratifications framework, adolescent users of these technologies who perceive them to be high in utility will be more motivated to use them and presumably use them more often and for longer periods of time (Blumler, 1979; Rubin, 1993). This is particularly important when considering the possible risks of social networking site use among adolescents. As noted by Barbosa et al. (2013), large numbers of adolescents do post controversial and potentially self-identifying information on their profiles. Therefore, any research that illuminates predictors can be used to inform interventions and information campaigns that teach adolescents about the possible issues with posting such information (see Moreno et al., 2009).

More so than computers, it makes sense that mobile technologies would be perceived by adolescents to be more useful, because they allow the adolescent to remain connected with friends online wherever they go. Since owning these technologies allows adolescents to update their profiles on the go, it follows that owning these technologies would be related to increased communication practices online. Here, the adolescent can quickly post a status update about the concert they are attending, the class they are sitting in, or the sporting event they are watching. Based on the results of the present study, it might not necessarily be the privacy of ownership that is related to these communication practices, specifically constructive communication, but rather, the addition of the convenience and features of certain technologies. That is not to say that privacy is not important; while mobile technologies allow for communicating on the go, they also allow the user to communicate in relative privacy if they so choose. The results of this study would seem to add to and extend to previous findings, indicating that perhaps both general ownership of technology as well as ownership of specific mobile technologies relates to constructive communication practices on social networking sites. Taken together with previous research, it seems that both the privacy and the convenience of mobile technologies may be related to both social media use and communication practices online. Therefore, the results of this study can be used to better understand the predictors of both social media use and online commu- 
nication practices among adolescents. By focusing on demographic, technology access, and technology ownership predictors of adolescents' social networking site use and communication practices, the present study adds to the current body of literature focusing on social and psychological predictors of use of and attitudes toward social networking sites (e.g., Gangadharbatla, 2008; Ljepava, Orr, Locke, \& Ross, 2013).

\subsection{Limitations and Future Research}

Although efforts were made by the market research company to recruit participants from around the United States, the overall sample was not representative because it was only sent to parents of adolescents who had signed up on an online website. Despite this limitation to the sample, however, it must be noted that the sample was national in scope, and was not biased toward gender, age, or race. Additionally, as it was an online survey, the sample is biased against adolescents who do not have access to the Internet, although research indicates that this is generally a small percentage (Lenhart et al., 2010). Finally, this survey was originally collected for the purposes and uses of the Museum of Science and Industry, Chicago, prior to the collaboration with the authors at Northwestern University. As a result, when analyzing the data for the purposes of this particular study the authors were limited by the specific questions asked in the original study.

Future research should continue to explore the relationship between ownership, access, and teen social media use. While the present study indicated some predictors of social media use, we did not measure exactly what adolescents were saying in either their constructive or non-constructive communications. Therefore, future research should examine other types of predictors, including social and psychological measures, that may play a role in youth's communication practices on social networking sites as well as explicitly what youth are saying in their communication online. Given the literature cited throughout this paper, it is likely that adolescents use such communications online to engage in a range of practices. As indicated by Valkenburg and Peter (2008), it is possible that the adolescents in this sample used constructive communication practices to explore their identity while connecting to others. It is also possible that they used constructive communication practices to post possibly sensitive information about themselves. Therefore, using this study as a basis, future research can and should continue to examine the exact communication practices of adolescents on social networking sites, relating it to both positive and negative outcomes.

\subsection{Conclusions}

Overall then, results from this study indicate that demographics, such as gender, media accessibility, and certain types of media ownership are all related to increases in social media use among adolescents. Additionally, these predictor variables are also related to heightened communication practices online, which include posting pictures, commenting on friends' walls, and updating one's status. Given the mixed findings regarding adolescent communication practices on social networking sites, it is important to understand predictors of both social media site use and communication practices on those sites.

\section{Acknowledgements}

The original version of this article was published in Media \& Communication with Librello Publishing House (2013, Volume 1, Issue 1).

\section{Conflict of Interests}

The authors declare no conflict of interests.

\section{References}

Barbosa A, O'Neill B, Ponte C, Simões JA, \& Jereissati T. (2013). Risks and safety on the Internet: Comparing Brazilian and European children. EU Kids Online: London, UK.

Beasley, S. \& Conway, A. (2011). Digital media in everyday life: A snapshot of devices, behaviors, and attitudes. Chicago, IL: Museum of Science and Industry.

Blumler, J. G. (1979). The role of theory in uses and gratifications studies. Communication Research, 6, 9-36. doi: 10.1177/009365027900600102

boyd, d. m. \& Ellison, N. B. (2008). Social networking sites: Definition, history, and scholarship. Journal of Computer-Mediated Communication, 13, 210-230. doi:10.1111/j.1083-6101.2007.00393.x

Christofides, E., Muise, A., \& Desmarais, S. (2011). Information disclosure and control on Facebook: Are they two sides of the same coin or two different processes? CyberPsychology \& Behavior, 12(3), 341345. doi: $10.1089 / c p b .2008 .0226$

Cingel, D. P., \& Sundar, S. S. (2012). Texting, techspeak, and tweens: The relationship between text messaging and English grammar skills. New Media \& Society, 14(8), 1304-1320. doi:10.1177/1461444812442927

Common Sense Media (2012). Social media, social life: How teens view their digital life. Retrieved September 25, 2012 from: http://www.commonsense media.org/research/socialmedia-social-life

Gangadharbatla, H. (2008). Facebook me: Collective self-esteem, need to belong, and Internet selfefficacy as predictors of the iGeneration's attitudes toward social networking sites. Journal of Interactive Advertising, 8(2), 5-15. doi: 10.1080/15252019. 2008.10722138

Goff, K. G. (2009). Social networking benefits validated. The Washington Times. Retrieved September 25, 
2012 from: www.washingtontimes.com/news/2009/ jan/28/socialnetworking-benefits-validated/?page=all

Hargittai, E. (2007). Whose space? Differences among users and non-users of social network sites. Journal of Computer-Mediated Communication, 13(1), 276297. doi:10.1111/j.1083-6101.2007.00396.x

Katz, E., Blumler, J. G., \& Gurevitch, M. (1974). Utilization of mass communication by the individual. In J. G. Blumler \& E. Katz (Eds.) The uses of mass communications: Current perspectives on gratifications research (pp. 19-32). Beverly Hills, CA: Sage.

Lapsley, D. K., FitzGerald, D. P., Rice, K. G., \& Jackson, S. (1989). Separation individuation and the "new look" at the imaginary audience and personal fable: A test of an integrative model. Journal of Adolescent Research, 4(4), 483-505. doi: 10.1177/074355488944006

Lenhart, A. (2009a). Teens and social media: An overview. Washington, DC: Pew Internet \& American Life Project.

Lenhart, A. (2009b). Adults and social network websites. Washington, DC: Pew Internet \& American Life Project.

Lenhart, A., Ling, R., Campbell, S., \& Purcell, K. (2010). Teens and mobile phones. Washington, DC: Pew Internet \& Life Project.

Lenhart, A. \& Madden, M. (2007). Teens, privacy and online social networks: How teens manage their online identities and personal information in the age of MySpace. Washington, DC: Pew Internet \& Life Project.

Lenhart, A., Purcell, K., Smith, A., \& Zickuhr, K. (2010). Social media and mobile Internet use among teens and young adults. Washington, DC: Pew Internet \& American Life Project.

Livingstone, S. (2008). Taking risky opportunities in youthful content creation: Teenagers' use of social networking sites for intimacy, privacy, and selfexpression. New Media \& Society, 10(3), 393-411. doi: $10.1177 / 1461444808089415$

Livingstone, S. (2009). Children and the Internet. Cambridge, UK: Polity Press.

Ljepava, N., Orr, R. R., Locke, S., \& Ross, C. (2013). Personality and social characteristics of Facebook nonusers and frequent users. Computers in Human Behavior, 29(4), 1602-1607. doi: 10.1016/j.chb.2013. 01.026

Madden, M., Lenhart, A., Cortesi, S., Gasser, U., Duggan, M., Smith, A. Beaton, M. (2013). Teens, social media, and privacy. Washington, DC: Pew Internet \& American Life Project.

Moreno, M. A., VanderStoep, A., Parks, M. R., Zimmerman, F. J., Kurth, A., \& Christakis, D. A. (2009). Reducing at-risk adolescents' display of risk behavior on a social networking web site: A randomized controlled pilot intervention trial. Archives of Pedi- atrics and Adolescent Medicine, 163(1): 35-41. doi: 10.1001/archpediatrics.2008.502

Palmgreen, P., Wenner, L. A., \& Rosengren, K. E. (1985). Use and gratifications research: The past ten years. In K. E. Rosengren, L. A. Wenner, \& P. Palmgreen (Eds.), Media gratifications research: Current perspectives (pp. 11-37). Beverly Hills, CA: Sage.

Patchin, J. W., \& Hinduja, S. (2010). Trends in online social networking: Adolescent use of MySpace over time. New Media \& Society, 12(2), 197-216. doi:10.1177/1461444809341857

Pempek, T. A., Yermolayeva, Y. A., \& Calvert, S. L. (2009). College students' social networking experiences on Facebook. Journal of Applied Developmental Psychology, 30, 227-238. doi: 10.1016/j.appdev.2008. 12.010

Peter, J., Valkenburg, P. M., \& Schouten, A. P. (2006). Characteristics and motives of adolescents talking with strangers on the Internet. CyberPsychology \& Behavior, 9(5), 526-530. doi: 10.1089/cpb.2006.9.526

Rideout, V. R., Lauricella, A. R., \& Wartella, E. (2011). Media use among White, Black, Hispanic, and Asian American children. Center on Media and Human Development, School of Communication, Northwestern University. Evanston, IL.

Rosenberg, J. \& Egbert, N. (2011). Online impression management: Personality traits and concerns for secondary goals as predictors of self-presentation tactics on Facebook. Journal of Computer-Mediated Communication, 17(1), 1-18. doi: 10.1111/j.10836 101.2011.01560.x

Rubin, A. M. (1993). Audience activity and media use. Communication Monographs, 60, 98-105. doi: 10.1080/03637759309376300

Sullivan, H. S. (1953). The interpersonal theory of psychiatry. New York, NY: Norton.

Valkenburg, P. M. \& Peter, J. (2007). Preadolescents' and adolescents' online communication and their closeness to friends. Developmental Psychology, 43(2), 267-277. doi:10.1037/0012-1649.43.2.267

Valkenburg, P. M., \& Peter, J. (2008). Adolescents' identity experiments on the Internet: Consequences for social competence and self-concept unity. Communication Research, 35(2), 208-231. doi: 10.1177/ 0093650207313164

Valkenburg, P. M., Peter, J., \& Schouten, A. P. (2006). Friend networking sites and their relationship to adolescents" well-being and social self-esteem. $C y$ berPsychology \& Behavior, 9(5), 584-590. doi: 10.1089/cpb.2006.9.584

Whitlock, J. L., Powers, J. L., \& Eckenrode, J. (2006). The virtual cutting edge: The Internet and adolescent self-injury. Developmental Psychology, 42(3), 407417. doi:10.1037/0012-1649.42.3.407 


\section{About the Authors}
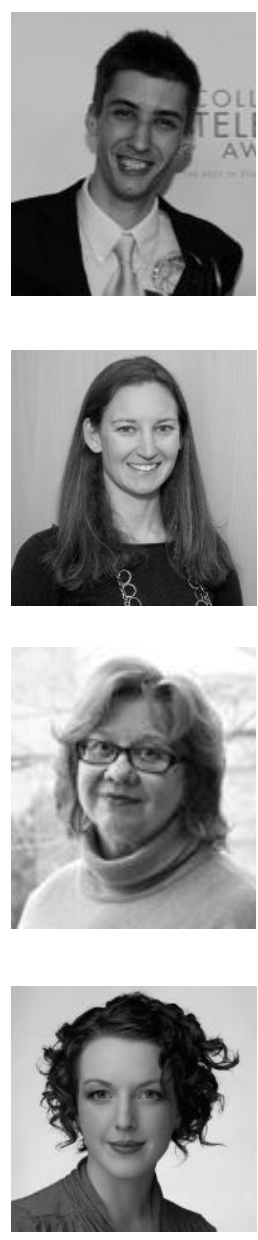

\section{Drew P. Cingel}

Drew Cingel is a second year PhD student in the Media, Technology, and Society program at Northwestern University. Prior to coming to Northwestern, Drew received an MA in Communication from Wake Forest University, and a BA in Psychology and a BA in Media Studies/Media Effects from Penn State University. His areas of research include adolescent-peer relationships, and peer influence, on social networking sites, children's learning from tablet computers, and the impact of television on children's moral reasoning.

\section{Alexis R. Lauricella}

Dr. Alexis R. Lauricella is the Associate Director of the Center on Media and Human Development at Northwestern University and a Lecturer in the department of Communication Studies. Dr. Lauricella earned her Ph.D. in Developmental Psychology and her Master's in Public Policy from Georgetown University. Her research focuses on children's learning from media and parents' and teachers' attitudes toward and use of media with young children.

\section{Ellen Wartella}

Dr. Ellen Wartella is the Sheikh Hamad bin Khalifa Al-thani Professor of Communication and Professor of psychology, human development and social policy, and medical social sciences at Northwestern University. She is Director of the Center on Media and Human Development and chair of the Department of Communication Studies. She is a leading scholar of the role of media in children's development and serves on a variety of national and international boards and committees on children's issues. She is co-principal investigator on two National Science Foundation grants.

\section{Annie Conway}

Annie Conway is the Director of Digital Learning and Engagement at The Chicago Architecture Foundation, where she leads the design and integration digital media into public engagement and learning initiatives. Her background is in designing digital tools to support informal learning in physical, digital, and blended environments. Annie has a B.A. in Children's Media and an M.A. in Digital Media Design for Learning from NYU and is a professor of Media Studies. 